\title{
DUPLICACIÓN DEL CUADRADO Y EL VOLUMEN DE SÓLIDOS EN EL CÓDICE ATLÁNTICO DE LEONARDO DA VINCI: UN ESTUDIO DE LA HOJA 100r
}

\author{
Jeová Pereira Martins \\ Jeovapereira80@outlook.com \\ Universidade Federal do Pará
}

Recibido: 19/12/2019 Aceptado: 17/02/2020

\begin{abstract}
Resumen
En este artículo son presentados resultados parciales de una investigación que tomó como base epistemológica los estudios sobre fuentes históricas textuales discutidos por Barros (2004), en este caso, el Códice Atlántico de Leonardo da Vinci con foco en el uso de la historia para la enseñanza de la Matemática. El objetivo central fue interpretar las imágenes representadas en la hoja 100r en busca de las relaciones geométricas que puedan emerger, con el fin de movilizarlas para las aulas de matemática (enseñanza de la geometría) en la Educación Básica, por medio de la problematización de los dibujos y anotaciones en la hoja. El material fue una copia impresa del manuscrito de Da Vinci que contienen 111 hojas e dibujos y anotaciones dentro de las cuales, en este artículo, analizamos la hoja 100r en la cual Leonardo presenta dos temas centrales: la duplicación del cuadrado y las relaciones entre los volúmenes de sólidos. La investigación documental realizada tuvo como fundamentos para la interpretación del lenguaje registrado en la hoja estudiada, elementos de la semiótica de C. S. Peirce a partir de Santaella $(1995,2012)$. Los resultados apuntan para la posibilidad del establecimiento de relaciones entre la geometría reflejada en el Códice Atlántico de Leonardo da Vinci y la geometría de la Educación Básica con foco en la elaboración de actividades de enseñanza a partir de la problematización (Miguel \& Mendes, 2010) de la geometría histórica identificada en el Códice Atlántico.
\end{abstract}

Palabras clave: Historia de las matemáticas, Enseñanza de las matemáticas, Geometría, Leonardo da Vinci.

\section{DUPLICATION OF THE SQUARE AND THE VOLUME OF SOLIDS IN LEONARDO DA VINCI'S ATLANTIC CODEX: A STUDY OF THE 100r SHEET}

\begin{abstract}
This article presents partial results of a wider research whose epistemological foundations were the studies on historical text sources discussed by Barros (2004), and which was based on Leonardo da Vinci's Atlantic Codex, focusing on History for the teaching of Mathematics. The main objective was to interpret the images presented on leaf 100r, aiming to find possible geometric relations, and mobilize them during mathematics classes - namely, in geometry lessons - both in Elementary and High School, problematizing the drawings and notes in the
\end{abstract}


aforementioned leaf. Our source was a printed copy of Da Vinci's manuscript containing 1119 leaves of drawings and notes. Among these is leaf 100r, which we analyze in this article. In it, Leonardo presents two central themes: the duplication of the square and the relations between solid volumes. The documented research we accomplished based the interpretation of the language used in leaf 100r on some elements of C. S. Peirce's semiotics, as defined by Santaella $(1995,2012)$. The results point out the possibility of establishing relations between the geometry we find on Leonardo da Vinci's Atlantic Codex and the geometry studied at the Elementary and High School level, focusing on the elaboration of teaching activities based on the problematization (Miguel \& Mendes, 2010) of the historical geometry one finds on the Atlantic Codex.

Keywords: History of Mathematics, Mathematics teaching, geometry, Leonardo da Vinci.

\section{A DUPLICAÇÃO DO QUADRADO E O VOLUME DE SÓLIDOS NO CÓDICE ATLÂNTICO DE LEONARDO DA VINCI: UM ESTUDO DA FOLHA 100r}

\section{Resumo}

O presente artigo apresenta resultados parciais de uma pesquisa mais ampla, que tomou como base epistemológica os estudos sobre fontes históricas textuais discutidos por Barros (2004), concretizado no Códice Atlântico de Leonardo da Vinci, com foco no uso na história para o ensino de Matemática. O objetivo central foi interpretar imagens representadas na folha 100r em busca de relações geométricas que possam emergir, a fim de mobilizá-las para as aulas de matemática (ensino de geometria) na Educação Básica, por meio da problematização dos desenhos e anotações da folha. O material empírico foi uma cópia impressa do manuscrito de Da Vinci que contém 1119 folhas de desenhos e anotações dentre os quais, neste artigo, analisamos a folha 100r na qual Leonardo apresenta dois temas centrais: a duplicação do quadrado e as relações entre volumes de sólidos. A pesquisa documental realizada tomou como fundamentos para a interpretação da linguagem registrada na folha em estudo, elementos da semiótica de C. S. Peirce a partir de Santaella (1995, 2012). Os resultados apontam para a possibilidade do estabelecimento de relações entre a geometria refletida no Códice Atlântico de Leonardo da Vinci e a geometria da Educação Básica com foco na elaboração de atividades de ensino a partir da problematização (MIGUEL \& MENDES, 2010) da geometria histórica identificada no Códice Atlântico.

Palavras-chave: História da Matemática, Ensino da matemática, Geometria, Leonardo da Vinci.

\section{Introdução}

O presente artigo apresenta resultados e reflexões parciais sobre uma pesquisa mais ampla cujo objeto de estudo é o Códice Atlântico, um manuscrito de Leonardo da Vinci (1452 - 1519) com desenhos e anotações sobre estudos por ele realizados ao longo de mais de 40 anos, sobre temas como ciência dos pesos, anatomia, óptica, balística, arquitetura e geometria. Em nosso trabalho esse manuscrito é uma fonte textual histórica tomado como objeto de 
estudo segundo a perspectiva da fonte como "discurso", ou seja, como portadoras de informações em si, cujo texto (no sentido ampliado) é abordado qualitativamente na busca por informações que estão submersas em suas camadas complexas, não apenas na superfície (BARROS, 2004, p. 135).

Adentrar essa camadas foi possível a partir de uma interpretação dos desenhos e anotações de Leonardo (o texto) embasada em elementos da Semiótica de C. S. Peirce (18391914) entendida como uma ciência que toma como objeto de estudo a linguagem em todas as suas formas e se interessa em revelar como tais linguagens e se organizam para produzirem significações e sentidos no pensamento do observador que passa por uma experiência, ou seja, que tem contato com um determinado tipo de linguagem, aqui de forma específica, a linguagem imagética e textual registrada por Leonardo da Vinci no papel, nas folhas do Códice Atlântico (SANTAELLA, 1995).

A interpretação dessa linguagem foi mediada por uma "arqueologia" (BARROS, 2004, p. 32) que buscou pequenos indícios no texto de Leonardo e os reuniu em um todo que evidenciou aspectos históricos da matemática, pois se trata de um manuscrito do século XV que, além de conter uma matemática do passado, contém, também, os fundamentos dessa matemática que remetem a Grécia antiga, como por exemplo, a folha 100r cujo conteúdo se relaciona com proposições de Os elementos de Euclides (300 a.C.). Essa matemática histórica será mobilizada para o ensino de geometria da Educação Básica, por meio de atividades de Ensino no formato de problematizações segundo Miguel e Mendes (2010).

Em síntese, o que defendemos aqui é que: a interpretação dos desenhos e anotações de Leonardo trazem à tona uma geometria do passado (histórica) que pode ser posta em correspondência com a geometria escolar (atual) por meio de problematizações, indagações provoquem o estabelecimento de relações. Esse movimento que relaciona: a história da matemática, os desenhos de Leonardo, a geometria escolar e o ensino de geometria, é o que poderá contribuir para que o ensino seja praticado da maneira mais eficiente possível, ou seja, que os estudantes apreendam os temas de geometria ensinados e formulem seus conceitos sobre tais temas.

Dessa forma, nosso objetivo é mobilizar a geometria que emerge da interpretação da folha 100r para o ensino de geometria na Educação Básica, por meio da problematização dos desenhos e anotações da folha. Essa mobilização de elementos históricos para o ensino de 
matemática, uma das características deste trabalho, é uma linha de pensamento que vem permeando pesquisas brasileiras em História da Matemática, pois há um número significativo de estudos em História da Matemática com foco no ensino, por isso, tais trabalhos foram categorizados por Mendes (2015) na tendência história da matemática para o ensino. Portanto, o trabalho que fizemos com a folha 100r do Códice Atlântico tem esse cunho histórico.

O Códice Atlântico é formado por 1119 folhas (em torno de 1750 fragmentos) que tratam de anotações de Leonardo reunidas em um único volume por Pompeo Leoni no final do século XVI em Milão e que passou por processos de restauração e de reorganização até chegar ao formato atual que se encontra na Biblioteca Ambrosiana de Milão. Recebe o nome de Códice Atlântico por se tratar de um manuscrito (códex) em folhas no formato atlântico, ou seja, de dimensões $65 \mathrm{~cm}$ x $44 \mathrm{~cm}$ e pela inscrição que aparece na capa da encadernação original do século XVI.

DISEGNI DI MACHINE ET / DELLE ARTI SECRETI . ET ALTRE COSE / DI LEONARDO DA VINCI / RACOLTI DA/ POMPEO LOE / NI (Desenhos de máquinas e de artes secretas e outras coisas de Leonardo da Vinci recompilados por Pompeo Leoni (Sànchez \& Almarza, 2008, p. 6-7).

Dentre as edições do Códice Atlântico produzidas pelo mundo a da Editora Fólio de Barcelona (em fac-símili) contém todas as 1119 folhas em 20 volumes com descrição, transcrições e os aparatos críticos de Algusto Marinoni. Desta edição foi organizada uma edição brasileira, que conta com 10 volumes que contemplam as 602 primeiras folhas do Códice Atlântico as quais tomamos como objeto de um estudo exploratório inicial para que se conhecesse o conteúdo das folhas e a partir daí se decidisse qual a melhor forma de se interpretar tal conteúdo.

Cada volume da edição do Códice que estudamos, contém um bloco de folhas de Leonardo (o volume 1, por exemplo, contém as folhas de 1 a 72) todas com reto (frente) e verso (rv) e, ao final desse bloco, páginas com um aparato crítico (referente a cada folha) que contém a descrição em português, a transcrição das anotações de Leonardo feita por Algusto Marinoni ${ }^{1}$ em italiano e algumas notas explicativas (Sànchez \& Almarza, 2008).

$\mathrm{O}$ aparato crítico mencionado foi fundamental para a interpretação que fizemos dos desenhos e anotações de Leonardo da Vinci, mas, como não foi feito com objetivos

\footnotetext{
1 Nas décadas de 1960 e 1970, ocorreu um processo restauro do Códice Atlântico que implicou na desencadernação do velho Códice e reencadernação em 12 volumes com os desenhos aos quais se acrescentaram outros 12 volumes de transcrições e aparatos críticos de Algusto Marinoni.
} 
relacionados a geometria e/ou seu ensino, naturalmente, foi necessária a elaboração de um instrumento de leitura para guiar o olhar e o pensamento sobre a folha com o propósito de atingir o objetivo proposto. Esse instrumento (Quadro A), consiste em um grupo de questões que representam algumas das quais ocorreram em meu pensamento quando olhei para a folha pela primeira vez e ocorrem toda vez que repito essa experiência, ou seja, essas questões são uma tentativa de materializar as interrogações que surgiram no meu pensamento quando me deparei com as folhas do Códice Atlântico particularmente a 100r. Mas é necessário esclarecer mais sobre isso!

Entendo como experiência o ato de olhar para os desenhos de Leonardo e, tal ato, causa algum tipo de impressão ou desequilíbrio no pensamento, provoca a criação de imagens mentais, signos que por sua vez criam significados no pensamento. O processo de significação mobiliza, também, conhecimentos do observador que auxiliam na interpretação e busca de significação para o que está sendo captado pelo olhar. Esse processo de significação, a semiose, ocorre no pensamento de quem observa os desenhos, que por sua vez são a materialização da semiose ocorrida no pensamento de quem os fez, Leonardo da Vinci (Santaella, 1995).

O que entendemos é que para que se interprete os desenhos de Leonardo, precisa se considerar que: os desenhos são produto da mente de Leonardo, fruto do processo de significação ocorrido no seu pensamento (semiose) a partir de suas experiências como artista e estudioso das Ciências. Tal processo é mediado pelas pressões internas (características da atividade artística e científica) e externas (fatores culturais e sociais) (Santaella, 1995) e por uma maneira de pensar característica de Leonardo, o pensamento por analogia, ou seja, a busca incessante por elementos que pudessem fundamentar sua arte e justificar a sua maneira de ser artista (Isaacson, 2017).

Por isso Leonardo estudava: ótica, em busca de melhor representar os efeitos da luz em seus quadros, com isso foi o pioneiro na técnica do sfumato; anatomia, para pintar corpos "perfeitos" e representar cada traço como pele, nervos ossos, veias, olhos e outras partes do corpo; e geometria para imprimir em suas pinturas a ideia de movimento. Essas pinturas eram chamadas de pintura psicológica pois transmitiam a sensação de sentimentos como dor, angustia, solidão, alegria, tristeza e sofrimentos e isso exigia do pintor que retratasse os corpos com músculos, braços, pernas, contorcidos, em movimento no plano e a solução para esse 
problema foi encontrada por Leonardo na geometria, pois, retratar os músculos em movimento, era alterar a sua forma mas manter seu volume e isso é o que ocorre na geometria que estuda a conservação do volume dos corpos. Um sólido geométrico pode ter sua forma alterada, mas seu volume mantido. Uma pirâmide pode ser transformada em um cubo de mesmo volume, assim como um cilindro pode ser transformado em um cone e vice-versa e isso foi mobilizado por Leonardo para a sua arte. Essas foram algumas das analogias que Leonardo fez entre as ciências e sua arte e que caracterizam a maneira de pensar desse Artista (Isaacson, 2017).

Assim, os desenhos de Leonardo ligados a geometria foram feitos no momento em que ele estudava, investigava a geometria em busca de analogias para sua atividade artística. Essa investigação (experimental) emitia resultados que eram por vezes parciais, incompletos ou conclusivos, mas de todo modo, eram as conclusões tiradas por Leonardo dos seus estudos que eram registradas, anotadas no suporte, o papel, na maioria dos casos por meio de desenhos, pois era a ferramenta que ele dominava como artista (Santaella, 1995, 2012).

Todos esses fatores precisam ser levados em consideração para a interpretação dos desenhos de Leonardo. Foram eles nos auxiliaram no método de interpretação dos desenhos e que consideramos para a elaboração do instrumento de leitura dos desenhos (quadro A) que é um "dispositivo de indagação" com o objetivo de desvendar as particularidades da linguagem, textual e imagética contida nas folhas do Códice Atlântico de Leonardo da Vinci aqui particularmente, a folha 100r (Santaella, 1995).

Quadro A: Instrumento de interpretação dos desenhos

\begin{tabular}{|c|l|}
\hline Impressões iniciais & $\begin{array}{l}\text { Que impressões a folha com desenhos de Leonardo lhe causa? Você acha que ela trata de } \\
\text { que? Ela lhe remete a algo familiar? O que ela lhe lembra? Que traços você identifica na } \\
\text { folha? Qual o seu conteúdo? Há desenhos e textos na folha? Você consegue ler o texto? } \\
\text { Você os reconhece os desenhos? }\end{array}$ \\
\hline Visão geral & $\begin{array}{l}\text { A folha tem uma pequena descrição! Essa descrição fala dos temas abordados na folha? } \\
\text { São desenhos geométricos? Maquinas de guerra? Maquinas para voar? Estudos sobre } \\
\text { Luz e sombra? Maquinas para o trabalho? Maquinas para submergir? Projetos } \\
\text { arquitetônicos? Desenhos sobre perspectiva? Projetos hidráulicos? Desenhos sobre } \\
\text { anatomia? }\end{array}$ \\
\hline $\begin{array}{c}\text { Motivações e } \\
\text { fundamentos }\end{array}$ & $\begin{array}{l}\text { O que teria levado Leonardo a realizar esses estudos e fazer essas anotações? } \\
\text { Por que Leonardo utilizava o desenho em seus estudos? } \\
\text { A folha faz referência a alguma fonte como um estudioso da época, um livro ou algum } \\
\text { trabalho específico em circulação na época? É possível ter acesso a essa fonte? As folhas } \\
\text { que não citam nenhuma fonte têm algum conteúdo que remete a alguma fonte da época? } \\
\text { Essa fonte trata matemática ou de geometria? Qual a relação dela com o conteúdo da }\end{array}$ \\
\hline
\end{tabular}




\begin{tabular}{|c|c|}
\hline & folha? \\
\hline Visão matemática & $\begin{array}{l}\text { Dentre os desenhos da folha há algum que remeta a matemática? A descrição da folha } \\
\text { fala de algum tema da matemática? Que matemática é refletida em cada desenho } \\
\text { observado? São cálculos aritméticos? Desenhos de geometria? Trigonometria? } \\
\text { Sequências numéricas? Ou outro tipo de matemática? }\end{array}$ \\
\hline Visão geométrica & $\begin{array}{l}\text { Dentre os desenhos sobre geometria, a que geometria se relacionam? Ponto, reta, plano, } \\
\text { circunferência, círculo, figuras geométricas planas, sólidos geométricos, quadratura do } \\
\text { círculo, quadratura do retângulo, duplicação do cubo, duplicação do quadrado? }\end{array}$ \\
\hline Detalhamento & $\begin{array}{l}\text { Todo o desenho da folha reflete algum objeto da geometria ou somente uma parte ou } \\
\text { desenho específico? Qual seria essa parte ou partes? }\end{array}$ \\
\hline $\begin{array}{l}\text { Possíveis relações } \\
\text { com a geometria } \\
\text { escolar }\end{array}$ & $\begin{array}{l}\text { A geometria identificada nos desenhos selecionados tem relação com a geometria } \\
\text { escolar? Quais seriam essas relações? Que geometria escolar pode ser mobilizada a partir } \\
\text { da "geometria de Leonardo"? Os livros didáticos de matemática contemplam essa } \\
\text { geometria? E os documentos curriculares? }\end{array}$ \\
\hline $\begin{array}{l}\text { Possibilidades para } \\
\text { o ensino }\end{array}$ & $\begin{array}{l}\text { Como possível mobilizar a "geometria de Leonardo" para o ensino? Que temas de } \\
\text { geometria podem ser ensinados na Educação Básica a partir dos desenhos geométricos } \\
\text { de Leonardo da Vinci? Como elaborar atividades de ensino a partir dos desenhos e } \\
\text { anotações de Leonardo? }\end{array}$ \\
\hline $\begin{array}{l}\text { Orientações ao } \\
\text { professor }\end{array}$ & $\begin{array}{l}\text { Que esclarecimentos, sobre o estudo feito com o desenho do Códice Atlântico, poderão } \\
\text { auxiliar o professor na implementação da proposta em suas aulas de geometria? }\end{array}$ \\
\hline
\end{tabular}

Fonte: Elaboração do autor

Todas essas questões serviram de guia para a interpretação dos desenhos da folha em estudo, mas além de guiar o olhar e o pensamento, elas também auxiliaram na explicação e na escrita deste texto que relata os resultados dessa interpretação. Assim, o texto que produzimos é a síntese das respostas de todas essas questões (do quadro A) e de outras que ocorreram no pensamento no momento da leitura dos desenhos e não pudemos captar e materializar na escrita.

Além das questões acima mencionadas, para o estudo da folha 100r seguimos alguns procedimentos práticos que consistiram em:

$\checkmark$ Descrição da folha com foco na geometria;

$\checkmark$ Marcações sobre a folha para melhor explicar o seu conteúdo;

$\checkmark$ Tradução da transcrição do texto de Leonardo, para verificar a relação do texto escrito com o desenho;

$\checkmark$ Elaboramos de desenhos a partir dos de Leonardo para facilitar o entendimento dos leitores e;

$\checkmark$ Explicação do conteúdo de geometria da folha relacionando-o com a geometria escolar Educação Básica. 


\section{1) Uma interpretação da folha 100r do Códice Atlântico de Leonardo da Vinci}

O estudo de áreas de figuras geométricas planas e do volume de sólidos, são temas aos quais Leonardo dedicou boa parte de seu tempo ao longo de anos. Esses estudos foram registrados por meio de desenhos e anotações como os da folha 100r do Códice Atlântico. Nela há dois temas predominantes: a construção de uma máquina de corte e a geometria, está última objeto de estudo neste texto. É possível que esses temas tenham relação pois o formato da lâmina de corte pode ter influência na sua eficiência, no entanto, em nosso estudo, não iremos considerar a possibilidade de correlação entre os temas, pois para atingir nosso objetivo, é suficiente considerarmos as possíveis relações entre os desenhos geométricos e as anotações de Leonardo na folha.

O verso da folha 100r não é legível, por isso, consideramos os desenhos do reto (figura 1) sobre o qual fizemos algumas marcações: três retas que dividem a folha em quatro partes indicadas pelos números 1, 2, 3 e 4 e as letras A, B, C e D que destacam 4 desenhos. Neste texto aprofundaremos somente o estudo da parte (2), considerando o texto e o desenho (B), e a parte 4 da qual consideramos apenas o desenho (E) por não encontrarmos correlação deste com o texto o que, vale ressaltar, é uma característica das anotações de Leonardo, pois ele fazia anotações de diferentes temas na mesma folha, ou seja, nem sempre há correlação entre as partes da folha como os desenhos e os textos escritos. 

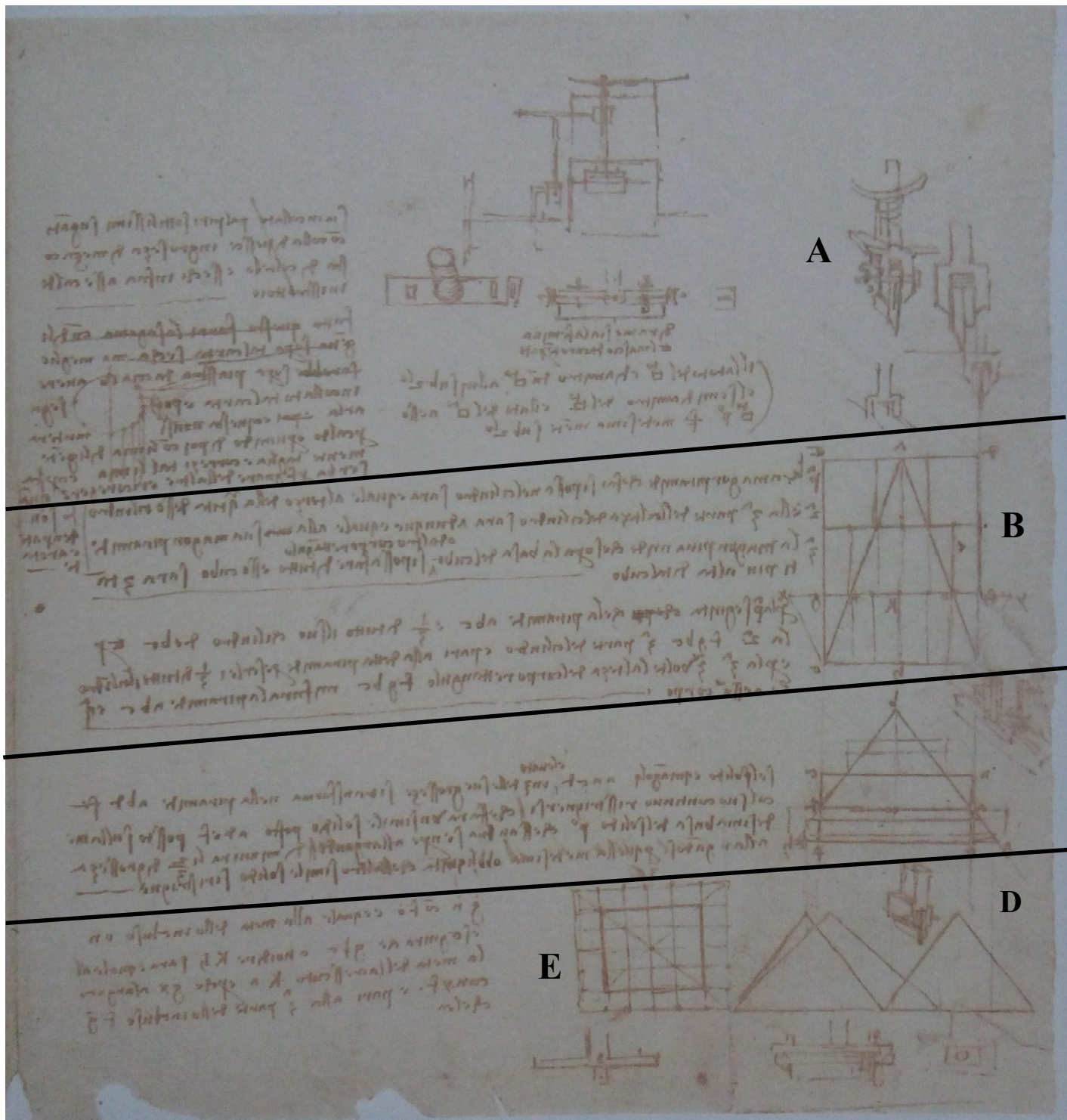

Fonte: Sànchez \& Almarza, 2008.

Na parte superior da folha (1) há um grupo de desenhos que se referem a construção de um escopro (A) que é um instrumento para corte, geralmente, utilizado no entalhe de materiais como madeira, pedra, mármore e metais, que pode ter sido pensado por Leonardo para ser utilizado em atividades como as de escultor, por exemplo, que era uma das artes praticadas na época. Além dos desenhos o texto que está próximo deles orienta sobre o procedimento de construção da ferramenta, como no trecho "faça este desenho em papel seco e cole sobre uma chapa de aço para marcá-la e depois cortá-la" (Da Vinci, apud Sànchez \& Almarza, 2008, p. 208). 
Abaixo do primeiro grupo de desenhos e anotações, do lado direito da folha, é possível observar a presença de quatro desenhos geométricos predominantes: (B) um triângulo inscrito em um retângulo subdividido em três porções retangulares e cada uma destas divididas em seis porções retangulares totalizado 18 porções que compõem área do retângulo; C) um triangulo com retângulos horizontais sobrepostos; (D) um grupo de três triângulos que se interceptam e; (E) um conjunto de dois quadrados concêntricos subdivididos em quadrados menores, um com 36 e outro com 16 porções quadradas. Os desenhos destacados estão na figura 1 que retrata a folha em estudo.

Como já mencionamos, a folha tem como temas a medição de áreas e volumes, mas essa medição não ocorre de maneira isolada que seria a apresentação de um determinado ente geométrico seguida do cálculo referente a sua área ou volume (no caso dos sólidos), Leonardo tem como foco, na folha, a duplicação do quadrado por meio de seus lados e diagonais e a relação entre prisma e pirâmide e entre cilindro e cone por meio dos volumes. Leonardo discute essas relações, fundamentado principalmente em Os elementos de Euclides, fato que detectamos por meio da tradução de suas anotações, em algumas das quais Leonardo faz enunciados equivalentes a algumas proposições de Os elementos.

Inicialmente destacamos a parte 2 da folha cujo texto trata da duplicação do quadrado que ocorre por uma relação entre lado e diagonal. É explicitada por Leonardo quando ele anota “o lado de um quadrado é o diâmetro de um quadrado subduplo e a metade do diâmetro do quadrado é o lado do quadrado a esse primeiro também subduplo"2. Ressaltamos que o diâmetro a que Leonardo se refere é a diagonal do quadrado e a palavra subduplo denota um quadrado com metade da área de outro quadrado dado. Leonardo não demostrou esse enunciado o que nos levou a fazê-lo (Leonardo, Apud. Sanchez \& Almarza, 2008, p. 208).

Poderemos expressar essa relação da seguinte maneira: 1) Dado um quadrado A de lado 1 , portanto, com área $1^{2}$. Sua diagonal será o lado de um quadrado B cuja área é o dobro da área do quadrado A, como consequência; 2) a medida da diagonal do quadrado B terá o dobro da medida do lado do quadrado A, ou seja, a semidiagonal do quadrado B tem medida igual ao lado do quadrado $\mathrm{A}$, o que pode ser demostrado a partir dos quadrados $\mathrm{ABCD}$ e A'B'C'D' da figura 2.

\footnotetext{
${ }^{2}$ Il lato del quadrato è diamitro d'un quadrato a lui subduplo. E'l semidiamitro del quadrato é 'I lato del quadrato a esso quadrato primo medesimamente subduplo.
} 
Figura 2: Quadrados ABCD e A'B'C'D'
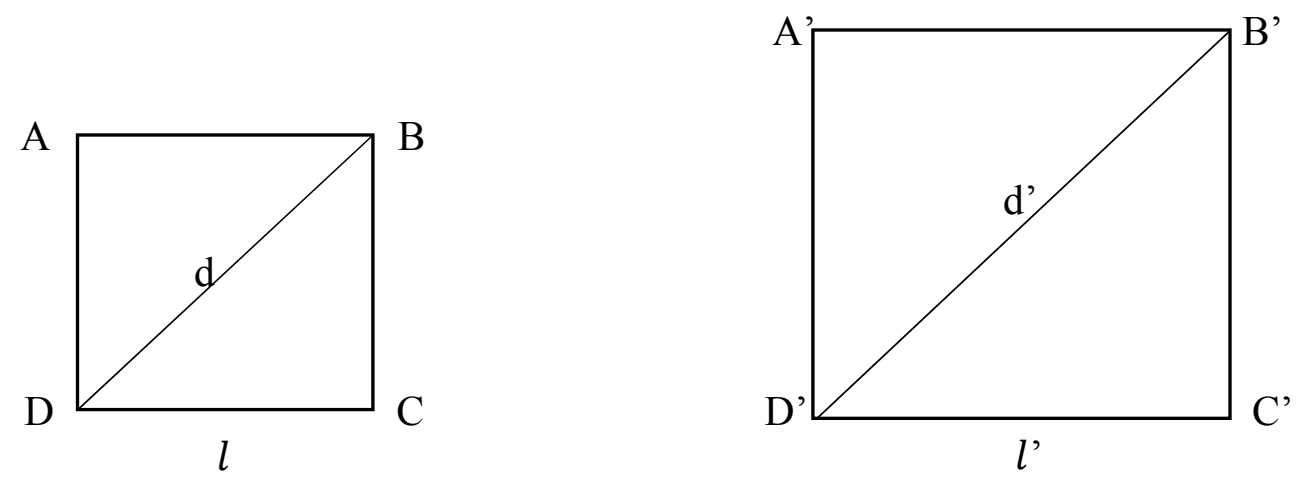

Fonte: Elaborado pelo autor

Façamos primeiro a prova da afirmativa 1 !

Considere o lado de $\mathrm{ABCD}$ é $l$. Como a área de um quadrado é medida pelo lado ao quadrado, a área de ABCD é $s_{1}=l^{2}$. Já a diagonal d pode ser determinada pelo teorema de Pitágoras, uma vez que $d^{2}=l^{2}+l^{2} \rightarrow d^{2}=2 l^{2} \rightarrow d=\sqrt{2 l^{2}} \rightarrow d=l \sqrt{2}$. Agora, considere o quadrado A'B'C'D' e suponha que seu lado l' tenha mesma medida da diagonal do quadrado ABCD, $l^{\prime}=l \sqrt{2}$, assim, a área de A'B'C'D' será $s_{2}=(l \sqrt{2})^{2} \rightarrow s_{2}=2 l^{2} \mathrm{e}$, como $s_{1}=l^{2}$, conclui-se que $s_{2}=2 s_{1}$.

Façamos, agora, a prova da afirmativa 2 !

Agora precisamos mostrar que a diagonal de A'B'C'D' é o dobro do lado de ABCD. Novamente pelo teorema de Pitágoras $d^{\prime 2}=l^{\prime 2}+l^{\prime 2} \rightarrow d^{\prime}=l^{\prime} \sqrt{2}$, mas $l^{\prime}=l \sqrt{2}$, então $d^{\prime}=$ $l \sqrt{2} \cdot \sqrt{2} \rightarrow d^{\prime}=l \sqrt{4} \rightarrow d^{\prime}=2 l$ ou $l=\frac{d \prime}{2}$.

Como provamos as afirmações 1 e 2 , fica provado que um quadrado com lado igual a diagonal de um quadrado dado, terá área igual ao dobro da área do primeiro. Vale ressaltar que a duplicação do quadrado é um problema que remete a antiguidade grega e foi resolvido geometricamente, nesse período, de forma semelhante a que fizemos aqui, ou seja, pela construção de um quadrado com lado sobre a diagonal do quadrado que se deseja duplicar.

Esse problema antigo, faz parte da história da matemática e caracteriza parte de seu desenvolvimento na Grécia antiga. Ele foi trazido à tona pelos desenhos e anotações de Leonardo na folha 100r, ou seja, a discussão do problema foi disparada pelo estudo e interpretação do desenho que revelou uma geometria histórica. $\mathrm{O}$ que defendemos neste 
trabalho é que esse movimento que relaciona: a história da matemática, os desenhos de Leonardo, a geometria escolar e o ensino de geometria, é o que poderá contribuir para que o ensino seja praticado da maneira mais eficiente possível, ou seja, que os estudantes apreendam os temas de geometria ensinados e formulem seus conceitos sobre tais temas.

A princípio a duplicação do quadrado não tem relação com o estudo sobre volume feito na folha, porém, a duplicação do quadrado se relaciona com a duplicação do cubo, outro problema da Grécia antiga, cujas tentativas de resolução se utilizaram da solução da duplicação do quadrado. Ocorre que Leonardo ao estudar a conservação de volumes dos sólidos geométricos se deparou (em algum momento) com a duplicação do cubo e, por consequência com a duplicação do quadrado. Quando tentou demostrar (na folha 100r) a relação entre volume dos sólidos, lançou mão do que tinha conhecimento, para fazer tal demonstração, que se encontra (2) cujas anotações estão ao lado do desenho (B) do triângulo inscrito no retângulo, e serão estudadas a partir daqui (Isaacson, 2017).

Observamos que Leonardo organiza o texto por um procedimento com características de uma demonstração matemática uma vez que parte de algo já válido para provar o que pretende. $\mathrm{O}$ faz por meio de um procedimento lógico que consiste em três enunciados e uma conclusão organizados em 4 parágrafos, três com os enunciados que Leonardo identifica (primeira, segunda, terceira) e uma conclusão que sintetiza as três e as relaciona com o desenho ao lado. Estudaremos primeiro os três enunciados:

Primeira. A maior pirâmide que pode ser feita no cilindro será igual a um terço da quantidade do cilindro; Segunda. E a terça parte da altura do cilindro será, portanto, igual a sua maior pirâmide; Terceira. A pirâmide maior, sobre a base do cubo ou de outro corpo retangular, poderá ser transformada em um cubo cuja altura é a teça parte da altura da pirâmide (Da Vinci, Apud Sànchez \& Almarza, 2008, p. 208)³.

A primeira afirmação causa um estranhamento, inicialmente, pois, a relação conhecida se estabelece entre os volumes da pirâmide e de um prisma de mesma base e não entre pirâmide e cilindro. Para esclarecer tal situação consultamos duas edições em português de Os elementos de Euclides, Euclides (1944, 2009) ${ }^{4}$. Em Euclides (1944, p. 126) a definição XVIII do Livro XI afirma que "Pirâmide cônica é uma figura sólida, que fica formada pela revolução

\footnotetext{
${ }^{3}$ Prima. La maggior piramide che far si possa nel cilindro, sarà equale al terzo della quantitá d'esso cilindro; Seconda. E la terza parte dell'ealtezza del cilindro sarà adunque equale alla sua maggior pirâmide; Terza. La maggior piramide, che sopra la basa del cubo o d'altro corpo rettangulo si possa fare di tutto esso cubo, sarà tre tanti più alta di tal cubo.

${ }^{4}$ A de 1944 foi traduzida por Frederico Commandino e a de 2009 foi traduzida por Irineu Bicudo.
} 
inteira de um triângulo retângulo ao redor de um lado daqueles, que compreendem o ângulo reto [...]". Sabemos que a revolução completa de um triângulo retângulo em torno de um de seus catetos gera um cone, ou seja, o que é chamado de pirâmide cônica é o que se conhece como cone, atualmente. Isso pode ser comprovado por Euclides (2009, p. 482) no qual há a definição de cone cuja essência é a mesma da Euclides (1944), porém o termo pirâmide cônica não é usado, mas sim a palavra cone. Assim entendemos que ao mencionar o termo pirâmide na primeira afirmação, Leonardo não se refere a pirâmide e sim a pirâmide cônica, ou seja, ao cone cujo volume tem relação com o volume do cilindro.

Destacamos que o fato de Leonardo usar o termo pirâmide onde seria cone, pode ter ocorrido por dois fatores: por ser o termo "pirâmide cônica" o usual na época (como encontramos em Euclides (1944)) ou, por problemas relacionados a tradução de Os elementos de Euclides do grego ou do latim para a sua língua materna pois, a primeira edição impressa foi publicada, em Veneza (em latim) no ano de 1482 e pode ter sido adquirida por Leonardo, assim como outra edição de 1509 do frade italiano Luca Pacioli (1447-1517) com quem Leonardo conviveu na corte de Ludovico Sforza em Milão no período de 1496 a 1499 e com quem aprendeu geometria (Isaacson, 2017).

Assim, concluímos que quando Leonardo escreve "a maior pirâmide que pode ser feita no cilindro" ele se refere ao cone como o conhecemos atualmente. Dessa forma, nosso entendimento é que a relação que ele pretendia estabelecer na primeira afirmação é aquela entre os volumes do cilindro e do cone que, constam em Os elementos de Euclides na proposição 10 do Livro XII: "Todo cone é uma terça parte do cilindro que tem a mesma base que ele e altura igual" (Euclides, 2009, p. 543). Como se segue. 
Figura 3: Relação entre cilindro e cone

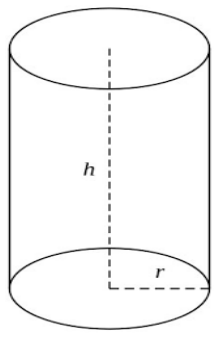

$S_{1}$

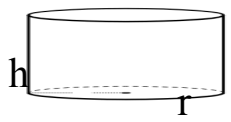

$S_{2}$

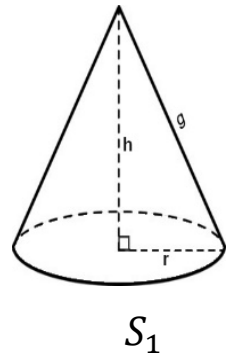

Fonte: Elaborado pelo autor

Considere os cilindros $S_{1}, S_{2}$ e o cone $S_{3}$ com mesmo raio $\left(r_{1}=r_{2}=r_{3}\right)$, cujas alturas são $h_{1}, h_{2}$ e $h_{3}$ e volumes são $V_{1}, V_{2}$ e $V_{3}$. Considere que a altura de $S_{2}$ é a terça parte da altura de $S_{1}$, ou seja, $h_{2}=\frac{h_{1}}{3}$. Como o volume do cilindro é o produto da área da base pela altura, ou seja, $V_{1}=A_{b} \cdot h \rightarrow V_{1}=\pi \cdot r_{1}{ }^{2} \cdot h_{1}$. Da mesma forma, $V_{2}=\pi \cdot r_{2}{ }^{2} \cdot h_{2}$. Mas $h_{2}=$ $\frac{h_{1}}{3}, \operatorname{logo}, V_{2}=\pi \cdot r_{1}{ }^{2} \cdot \frac{h_{1}}{3}$ que é equivalente a $V_{2}=\frac{1}{3} \pi \cdot r_{1}{ }^{2} \cdot h_{1}$, mas $\pi \cdot r_{1}{ }^{2} \cdot h_{1}=V_{1}$, portanto, $V_{2}=\frac{1}{3} v_{1}$. Sabe-se, ainda que o volume do cone é a terça parte do volume do cilindro $V_{3}=$ $\frac{1}{3} v_{1}$, mas como $V_{2}=\frac{1}{3} v_{1}, V_{3}=V_{2}$. Desta última relação pode-se afirmar, então que o volume de um cone é equivalente ao de um cilindro com mesma base e altura igual a terça parte do cone. Mas esta última relação é exatamente o que foi observado por Leonardo ne segundo enunciado "E a terça parte da altura do cilindro será, portanto, igual a sua maior pirâmide".

Seguindo essa mesma linha de raciocínio Leonardo estende a relação entre cilindro e cone para os sólidos, pirâmide e prisma, quando na terceira afirmação anota "a pirâmide maior, sobre a base do cubo ou de outro corpo retangular, poderá ser transformada em um cubo cuja altura é a teça parte da altura da pirâmide", ou seja, uma pirâmide tem volume equivalente ao de um cubo com um terço de sua altura desde que a pirâmide e o cubo tenham a mesma base.

Essa afirmação feita por Leonardo na folha 100r do códice atlântico, possivelmente, tem como fundamento o Livro XII de Os elementos cuja proposição VII é "Todo prisma, tendo um triângulo como base, é dividido em três pirâmides iguais entre si, tendo triângulos como bases" (Euclides, 2009, P. 539). Dessa forma, uma pirâmide com mesma base e altura de um dado prisma tem volume igual a terça parte do prisma, ou ainda, se o prisma for dividido em três partes de mesmo volume, cada um deles (prismas com um terço da altura do 
primeiro) terá volume equivalente ao da pirâmide em estudo. Essa relação é estendida para prismas e pirâmides que tenham bases diferentes dos triângulos, pois “[...] é evidente que toda pirâmide é uma terça parte do prisma que tem a mesma base com ela e igual altura [...]" o que também é feito por Leonardo na terceira afirmação (Euclides, 2009, p. 540).

Em Os elementos $(2009$, p. 539) a demonstração dessa relação é feita a partir de um desenho que retrata um prisma de base triangular que é seccionado de forma a originas as três pirâmides de mesmo volume. De forma análoga, essa demonstração é encontrada em alguns livros didáticos de matemática do Ensino Médio na Educação Básica visto que nem todos demostram essa relação e somente a apresentam de forma direta. O desenho mencionado é semelhante ao da figura 4 no qual a secção do prisma ABCDEF origina as pirâmides DEFA, ABCE e AEBF.

Figura 4: relação entre volume do prisma e da pirâmide
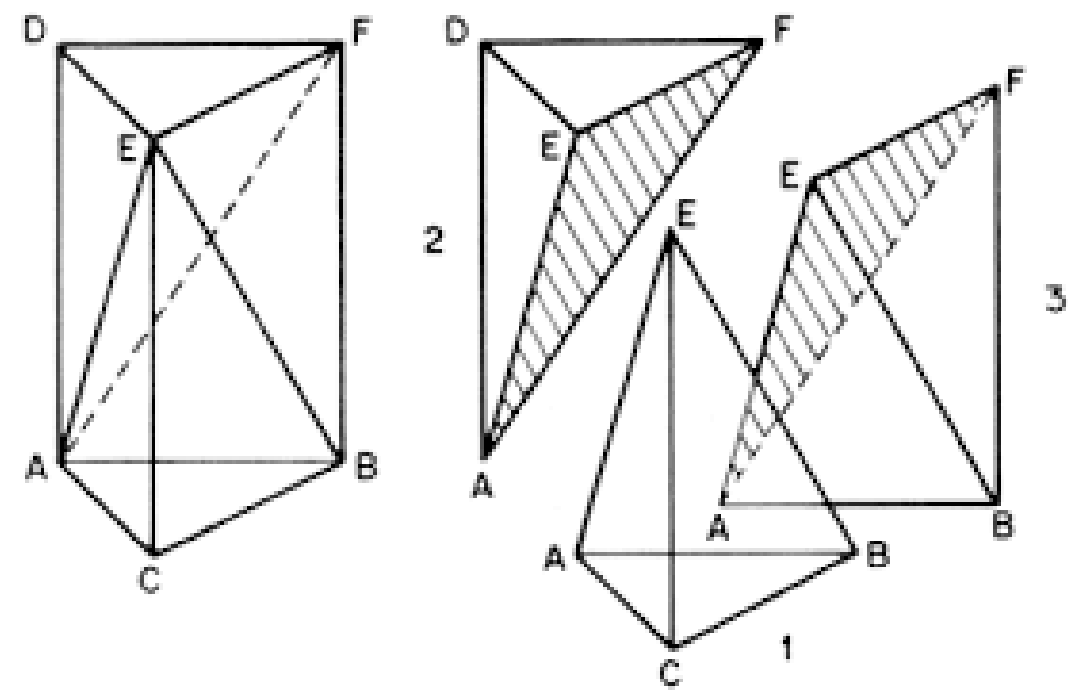

Fonte: Google imagens

Façamos tal demonstração, com o objetivo de reafirmar o que já foi provado por Euclides e fazer a conexão com os livros didáticos de matemática da Educação Básica uma vez que temos como foco o ensino de geometria nesse nível de ensino. Assim, demostraremos a partir de Euclides (2009, p 539-540) e Paiva (2015, p. 218-219).

Considere o prisma $\mathrm{ABCDEF}$ (figura 4) cujas bases são os triângulos $\mathrm{DEF}$ e $\mathrm{ABC}$ (congruentes) e cujas faces laterais são os quadriláteros ADFB, ACED e CBFE. Ocorre que cada face do prisma possui uma diagonal que divide cada uma delas em dois triângulos 
congruentes entre si. Assim, temos que: a diagonal AE de ACED originas os triângulos AEC e AED (congruentes); a diagonal $\mathrm{BE}$ origina os triângulos $\mathrm{BEC}$ e $\mathrm{BEF}$ (congruentes) e a diagonal $\mathrm{AF}$ origina os triângulos $\mathrm{ABF}$ e $\mathrm{ADF}$ (congruentes).

Considere, ainda que a secção desse prisma conforme, dá origem a três pirâmides ABCE (1), DEFA (2), e ABEF (3) todas de base triangular (figura 4). Precisamos provar que as pirâmides em estudo possuem o mesmo volume. Para essa prova, tomaremos como princípio a propriedade $\mathrm{P}_{1}$ segundo a qual, duas pirâmides triangulares de mesma altura e bases de mesma área têm o mesmo volume.

Pirâmides 1 e 2: As pirâmides ABCE (1) e DEFA (2) têm como bases DEF e ABC que são congruentes por serem as bases do prisma $\mathrm{ABCDEF}$. Mas os seguimentos $\mathrm{CE}$ e $\mathrm{AD}$ têm mesma medida já que são os lados paralelos do quadrilátero ACED e como são as alturas relativas as bases de (1) e (2), as pirâmides têm mesma altura.

Assim, Como (1) e (2) têm bases congruentes e mesma altura, por P1, têm o mesmo volume.

Pirâmides 2 e 3: Com já mencionamos a diagonal AF do quadrilátero ABFD origina os triângulos $\mathrm{ABF}$ e ADF que são congruentes e são as bases das pirâmides 2 e 3. Mas as alturas das pirâmides em estudo, são iguais à distância do ponto $\mathrm{E}$ até o plano que contém o quadrilátero ABFD.

Assim, as pirâmides 2 e 3 têm bases congruentes e mesma altura, portanto, por $\mathrm{P}_{1}$ têm mesmo volume.

Portanto, como a pirâmide (1) tem mesmo volume que a pirâmide (2) e a pirâmide (2) tem mesmo volume que a pirâmide (3), conclui-se que (1) e (3) tem mesmo volume. Logo as três pirâmides têm mesmo volume. Como elas foram originadas a partir da divisão de um prisma, cada uma delas terá volume equivalente a terça parte do volume do prisma.

Sendo $\mathrm{S}_{b}$ a área da base do prisma $\mathrm{ABCDEF}$ e $h$ sua altura, o volume do prisma $\mathrm{V}$ será $V=\mathrm{S}_{\mathrm{b}} \cdot \mathrm{h}$. Considerando o que foi demonstrado anteriormente, o volume da pirâmide $\mathrm{V}_{\mathrm{p}}$ será $\mathrm{V}_{\mathrm{p}}=\frac{1}{3} \cdot \mathrm{S}_{\mathrm{b}} \cdot \mathrm{h}$.

A essa altura o leitor deste texto pode estar se perguntando sobre o desenho B da folha 100r que está ao lado das três afirmações que acabamos de discutir. Não o mencionamos anteriormente pelo fato de que tal desenho não é mobilizado por Leonardo nas afirmações discutidas o que só é feito por ele no quarto momento no qual sintetiza o conteúdo das 
afirmações e as relaciona com o desenho B. Assim, retomaremos o desenho para fazer a discussão do trecho de anotações mencionado.

Para melhor interpretar o desenho, fizemos um modelo que expressa com clareza as ideias do desenho de Leonardo tendo vista que, por se tratar de um desenho do século XV, possui algumas partes apagadas. As letras $a, b, c, d, e, f$ e $g$ representam pontos e estão na forma minúscula por ser assim que Leonardo as utilizou em seus desenhos, mas no texto usaremos a notação atual para evitar confundi-las com o texto em si. Incluímos $i$ e $j$ para que a interpretação e a explicação, que faremos a partir do texto de Leonardo, sejam mais claras.

Figura 5: triângulo inscrito no retângulo
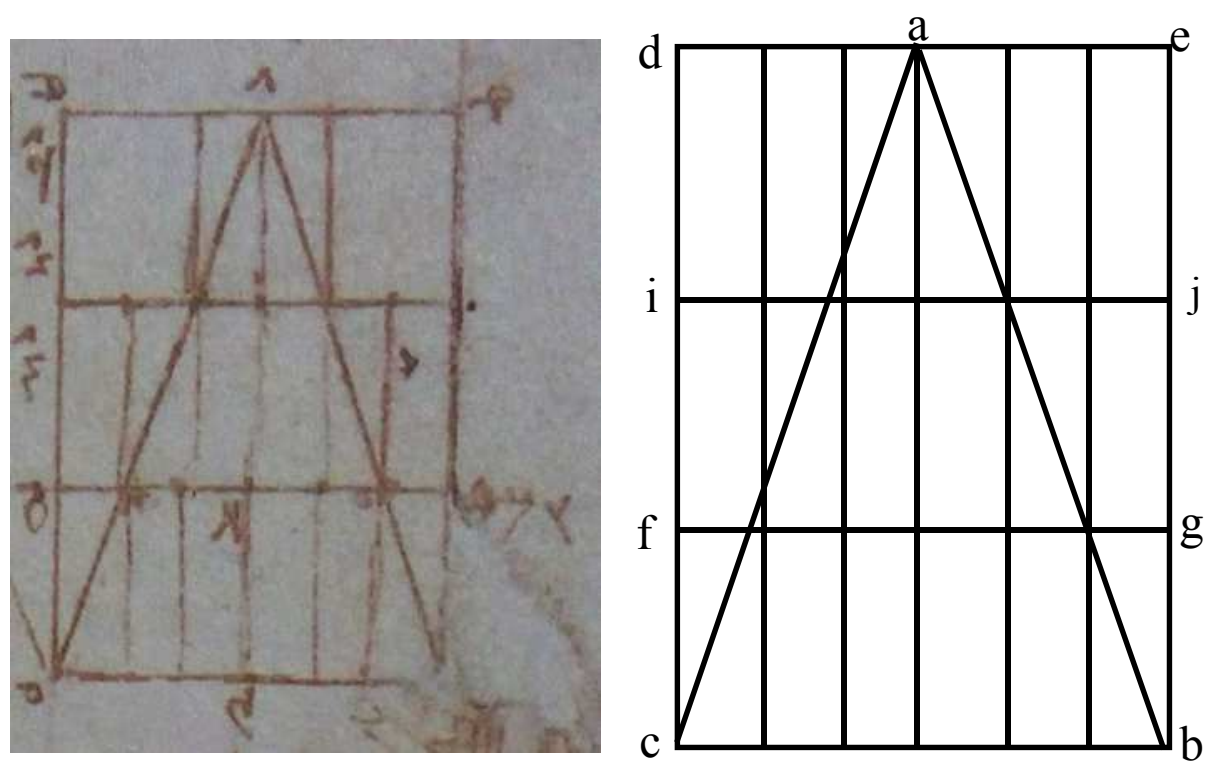

Fonte: Adaptado de Sànchez e Almarza, 2008.

É possível observar que para cada afirmação feita anteriormente ${ }^{5}$, Leonardo expressa uma consequência e a relaciona com o desenho, dessa forma, o desenho é a parte geométrica que compõe essa tentativa de demonstração ou verificação das definições e proposições de Os elementos de Euclides já mencionadas anteriormente.

A partir do desenho inferimos que o retângulo é a seção de um cilindro e de um prisma quadrangular, já o triangulo é a secção de uma pirâmide, cuja base coincide com a base do prisma, e de um cone cuja base coincide coma base de cilindro. Portanto, Leonardo tenta demostrar graficamente as proposições referidas por meio de uma superfície plana, ou seja,

\footnotetext{
${ }^{5}$ Citação da página 12.
} 
por meio das secções da pirâmide, do prisma, do cilindro e do cone (Sànchez \& Almarza, 2008).

A partir do desenho é possível constatar que Leonardo dividiu o retângulo maior DEBC em três retângulos menores FGBC, IJGF e DEJI e cada um destes em 6 retângulos menores que tomaremos como uma unidade de área (1u.a.), ou seja, cada um dos três retângulos, como FGBC por exemplo, tem área 6u.a. e o retângulo DEBC tem área 18u.a. É possível constatar, ainda, que os dois lados do triangulo ABC diferentes da base passam sobre as diagonais dos retângulos que tomamos como 1u.a. por isso tais diagonais dividem estes em duas partes de $\frac{1}{2}$ u.a. cada. Assim, é possível estabelecer a relação entre as áreas do triângulo ABC e do retângulo DEBC.

Observe o desenho, partindo da base CB do retângulo. No retângulo FGBC, pode-se inferir que o triangulo $\mathrm{ABC}$ ocupa 5u. a. (4u.a. mais duas metades 1u.a.). No retângulo IJGF o triangulo ocupa 2 u.a. mais duas metades 1u.a. que totaliza 3 u.a. e no retângulo DEJI, ABC ocupa duas metades do retângulo tomado como unidade de área, totalizando 1u.a. Por tanto, o triangulo $\mathrm{ABC}$ ocupa, no total, 9u.a. que corresponde à metade da área total do retângulo DEBC que é de 18u.a.

Vamos verificar, agora, a correlação da nossa interpretação com o que Leonardo fez na folha 100r. Em sua conclusão Leonardo diz que:

Pela primeira, a pirâmide $\mathrm{a} b \mathrm{c}$ é um terço de todo o seu cilindro $\mathrm{d}$ e b c; pela segunda, $\mathrm{f} \mathrm{g} \mathrm{b} \mathrm{c}$, terça parte do cilindro, é igual à referida pirâmide, por ser um terço de todo o cilindro e; pela terceira, três vezes a altura do corpo retangular $\mathrm{f} \mathrm{g} \mathrm{b} \mathrm{c,} \mathrm{mede} \mathrm{a} \mathrm{altura}$ da pirâmide a b c, igual a esse corpo (Sànchez \& Almarza, 2008, p. 208). ${ }^{6}$

A primeira parte na qual Leonardo diz que a pirâmide $\mathrm{ABC}$ é $\frac{1}{3}$ do cilindro DEBC não converge com nossa interpretação, pois nela ABC tem 9u.a. e DEBC, 18u.a., ou seja, ABC é $\frac{1}{2}$ de DEBC. Em seguida, ele fala que o retângulo FGBC é a terça parte do cilindro DEBC, o que converge com o que fizemos, pois FGBC mede 6u.a. e DEBC 18u.a. Na terceira parte da conclusão Leonardo diz que a altura da pirâmide ABC é o triplo da altura de FGBC, o que é provado pelo desenho, mas afirma também que $\mathrm{ABC}$ é igual a FGBC o que não converge com nossa interpretação na qual ABC tem 9u.a. e FGBC 6u.a.

\footnotetext{
${ }^{6}$ Per la prima seguita che la piramide $\mathrm{a} b \mathrm{c}$ è un terzo di tutto il suo chilindro $\mathrm{d}$ e $\mathrm{b} \mathrm{c}$; e per la seconda $\mathrm{f} \mathrm{g} \mathrm{b} \mathrm{c}$, terza parte del cilindro, è pari alla detta piramide, per esser lei un terzo di tutto il cilindro. E per la terza tre volte l'alteza del corpo rettangulo $\mathrm{g} \mathrm{b} \mathrm{c}$ misura la piramide $\mathrm{a} \mathrm{b} \mathrm{c}$, equale a esso corpo.
} 
As convergências e divergências entre a interpretação dos desenhos de Leonardo e aquilo que está na folha registrado por ele, não têm a intenção apontar falhas no seu trabalho ou minimizar sua importância, pois temos que considerar que Leonardo viveu nos séculos XV e XVI, portanto em outra época, com outra cultura e organização social e com outra matemática em circulação, ou seja, em condições de vida que não são as mesmas da contemporaneidade. Além disso, temos que levar em consideração os objetivos de Leonardo em fazer esses estudos. Dessa forma, as convergências e divergências apontadas, são elementos que podem ser utilizados na elaboração de atividades de ensino ou em discussões durante as aulas de geometria sobre o seu processo de desenvolvimento histórico.

O que queremos enfatizar é o procedimento que Leonardo segue, principalmente nessa parte específica da folha (2) na qual ele consegue completar uma linha de raciocínio, pois, ele define uma base teórica (Os elementos), anuncia o que vai tomar como válido, que são as três afirmações (primeira, segunda e terceira) e constrói a prova por meio de argumentos escritos e de um desenho que se relaciona com tais argumentos elaborados a partir do que ele tem como válido. A importância de tal procedimento está nas semelhanças que tem com a construção da própria matemática, por exemplo, a geometria de Os elementos, a qual parte de algo que já é válido, definições, postulados e noções comuns, para anunciar e provar as proposições.

Outro aspecto importante que destacamos são as incoerências ou divergências percebidas na demonstração de Leonardo quando ele utiliza figuras planas (seções dos sólidos), por exemplo, para provar algo relacionado a sólidos geométricos e chega a resultados que não provam totalmente o que ele pretendia. Novamente, um aspecto que pode ser relacionado ao desenvolvimento da matemática, visto que, esse corpo de conhecimento sólido e reconhecido na atualidade, passou por muitas tentativas e erros até chegar ao formato atual. O que queremos dizer é que tentativas, acertos e erros foram (e são) fatores primordiais para o desenvolvimento da matemática e inclusive responsáveis por gerar uma parte significativa da matemática de forma não intencional, mas como resultado de tentativas de solução de problemas matemáticos como os famosos problemas da antiguidade grega cujas tentativas de solução se estenderam por 2000 anos e geraram conhecimentos matemáticos como aqueles relacionados as cônicas, por exemplo.

Essa conclusão a que chegamos, poderá ser tema de discussão entre os estudantes da Educação Básica, mais precisamente do Ensino Médio já que esse assunto, geralmente, faz 
parte daqueles a serem ensinados nesse Nível. A discussão a que nos referimos, disparada pelos desenhos de Leonardo que refletem uma matemática histórica, poderá ter como mediadora a relação entre a geometria euclidiana de Os elementos e a geometria escolar do livro didático de matemática. Isso poderá fazer com que os estudantes compreendam as origens históricas da geometria que estudam na Escola Básica e passem a ter uma visão mais completa dessa geometria que não estará mais isolada (no livro didático) do seu contexto histórico.

Passemos ao estudo do desenho D que está na parte 4 da folha 100r (figura 1). $\mathrm{O}$ quadrado que estudaremos (figura 6) foi dividido em 36 quadrados pequenos com o número 36 acima escrito ao contrário, como já se sabe da escrita de Leonardo. O fato de o quadrado maior ser composto por 36 quadradinhos pode ser relacionado à obtenção da fórmula para cálculo de área do mesmo, pois, a base do quadrado é composta por 6 quadradinhos, assim como a altura e o produto da base pela altura é $6 \times 6=36$ que é exatamente o número total de quadradinhos que corresponde a área do quadrado. Assim, cada quadrado menor seria uma unidade de área 1u.a. como se constatar na figura 6.

Para que se compreenda a relação que estabelecemos, colocamos o desenho de Leonardo novamente ao lado de um esquema que possibilita o estabelecimento de relações com os temas de geometria da educação Básica.

Figura 6: desenho D da folha $100 \mathrm{r}$
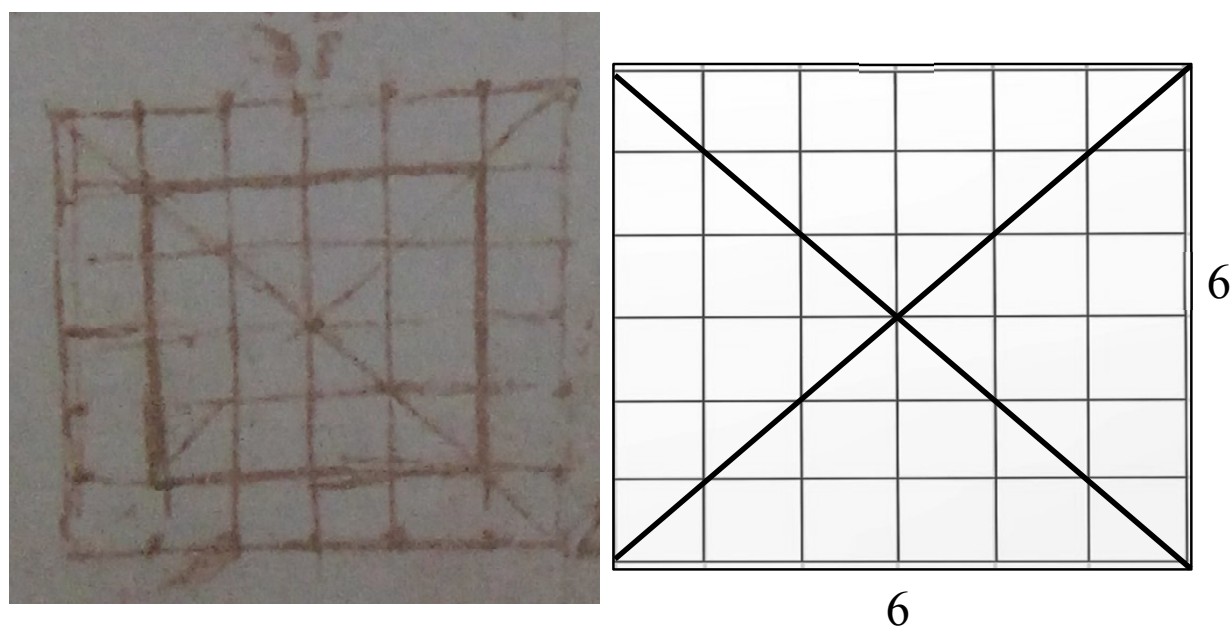

$$
\begin{gathered}
l^{2}+l^{2}=d^{2} \\
2 l^{2}=d^{2} \\
d=\sqrt{21^{2}} \\
d=l \sqrt{2}
\end{gathered}
$$

Fonte: Adaptado de Sànchez e Almarza, 2008

O método que foi utilizado por Leonardo ao dividir o quadrado em quadrados menores, é o mesmo utilizado no ensino de geometria da Educação Básica e que está retratado no 
quadrado da direita, pois como se sabe, a fórmula para cálculo da área do quadrado é o produto da base pela altura $A=b . h$ e como em um quadrado a base tem mesma medida da altura, a fórmula pode se $A=l^{2} \mathrm{r}$ sendo $l$ o lado do quadrado. Dessa forma, o desenho de Leonardo pode ser relacionado ao estudo de área do quadrado que se dá no Ensino Fundamental maior (6 ${ }^{\circ}$ ao $9^{\circ}$ ano) (BRASIL, 2018).

Além da medição de área, o desenho em discussão remete a outra relação contida no estudo do quadrado que é aquela entre o lado e a diagonal (já evidenciada neste texto) que aliás é um tema recorrente nos desenhos de Leonardo contidos no Códice Atlântico e em outros manuscritos seus como o Códice Windsor Essa relação é tema de estudo no $1^{\circ}$ ano do Ensino Médio, quando se estuda a geometria plana e no $2^{\circ}$ ano no estudo de prismas, uma vez que a diagonal de um prisma de base quadrada é obtida a partir da diagonal da sua base. A relação é feita por meio do teorema de Pitágoras, pois a diagonal do quadrado determina dois triângulos retângulo cuja hipotenusa é $d$ e os catetos têm medida $a$ (Sànchez \& Almarza, 2008).

Observe (na figura 6) que o desenho original possui o traçado das duas diagonais do quadrado, de forma semelhante ao que fizemos. Com a aplicação do teorema de Pitágoras, chegamos à relação entre lado e diagonal. Como o quadrado de Leonardo tem lado $6(\mathrm{a}=6)$, podemos calcular a medida da sua diagonal que seria $d=6 \sqrt{2}$.

Dessa forma, o desenho contido na folha 100r do Códice Atlântico, contém elementos que remetem à geometria da Educação Básica, pois tratam de temas que foram estudados por Leonardo (nos séculos XV e XVI) e continuam a ser tema de estudo atualmente na sala de aula de matemática da Educação Básica. Isso reflete o potencial desses desenhos para o ensino de geometria e a possibilidade de sua utilização para a elaboração de atividade de ensino de geometria.

A geometria plana refletida na folha 100r remete à temas de Geometria ensinados na Educação Básica dentre os quais destacamos: prisma, pirâmide, cilindro e cone, triângulo, retângulo, quadrado, medição de áreas, e outros como duplicação do quadrado e a relação entre volumes, triangulo retângulo e teorema de Pitágoras. São temas que fazem parte da geometria do Ensino Fundamental ( $6^{\circ}$ ao $9^{\circ}$ ano) e Ensino Médio.

Assim, o estudo da Geometria no Educação Básica pode reduzir-se a aplicação de fórmulas de cálculo de área e volume, por exemplo. Outros recursos como a equivalência de áreas, que já se pratica há milhares de anos por povos como os gregos antigos e mesopotâmios, 
possibilita transformar qualquer região poligonal plana em um quadrado com área equivalente. Os gregos chamavam esse método de fazer a quadratura de uma figura e propomos sua utilização no ensino de geometria na Educação Básica por meio dos estudos dos desenhos do Códice Atlântico de Leonardo da Vinci (BRASIL, 2018, p. 270-271).

Dessa forma, o estudo dos temas de geometria que fazem parte do currículo da Educação Básica poderão ser ensinados por meio de desenhos contidos em manuscritos antigos como os que contém o Códice Atlântico de Leonardo da Vinci, pois tais desenhos, mesmo não tendo sido feitos ou pensados para esse fim, têm em sua constituição, elementos que remetem ou refletem a geometria desse Nível de Ensino.

A exemplo disso, a demonstração da relação entre volume da pirâmide e do prisma, discutida neste texto, e o procedimento de Leonardo em sua demonstração, poderão ser discutidos nas aula com o objetivo de levar o estudante a desenvolver a habilidade de argumentar logicamente, ou seja, propor ideias, a partir de algo já provado e encadeá-las com foco na prova pretendida, que é uma mostra do funcionamento da matemática com ciência que pode ser objeto estudo no Ensino Médio como possibilidade de proporcionar aos estudantes conhecer um pouco sobre a epistemologia da matemática, de forma específica de uma prova em geometria, mas que pode ser estendida a outras áreas como a álgebra, por exemplo.

O que queremos dizer é que tanto o processo de demonstração quanto o estabelecimento de relações entre os sólidos que discutimos, poderá desenvolver nos estudantes do Ensino Médio habilidades e raciocínio mais complexos comparados aqueles desenvolvidos na atividade de conhecer os sólidos separadamente e ser informado sobre a existência do teorema, somente (que também é necessário). Isso caracteriza o aprofundamento das ideias sobre geometria adquiridas no Ensino Fundamental e, por tanto, a ampliação dos conhecimentos adquiridos pelo estudante o que poderá contribuir para que ele, diante de uma situação problema, tenha a sua disposição, um leque de possibilidades que lhe permita selecionar a melhor e mais eficiente para tal solução (BRASIL, 2007).

Mas como fazer as possíveis relações entre os desenhos de Leonardo e a geometria da Educação Básica (evidenciadas neste texto) emergirem nas aulas de matemática desse nível de ensino? Por meio da interpretação e da problematização desses desenhos com foco no ensino, ou seja, pela elaboração de atividades de ensino que mobilizem a geometria dos desenhos e as conecte a geometria escolar. 


\section{Problematizações para as aulas de Matemática na Educação Básica}

Nossa proposta é que os desenhos de Leonardo sejam interpretados e problematizados. As problematizações se materializam em atividades de ensino propostas para serem desenvolvidas em sala de aula (e para além dela) envolvendo a geometria dos desenhos de Leonardo conectadas a geometria escolar. Aqui tomaremos como fundamento as "Unidades Básicas de Problematização", UBP, propostas por Miguel e Mendes (2010, p 386). Segundo os autores,

Uma UBP nada mais é do que um flash discursivo memoralistico que descreve uma prática sociocultural situada em um determinado campo de atividade humana, e que teria sido de fato realizada para se responder a uma necessidade (ou desejo) que teria se manifestado a um ou mais integrantes de uma comunidade de prática, em algum momento do processo de desenvolvimento dessa atividade na história (tradução livre).

A UBP, como o próprio nome define, é uma unidade que serve de base para a problematização que são os questionamentos elaborados. A partir da descrição da prática sociocultural, da sua análise e identificação elementos que se deseja estudar é que se deve problematizar, por meio de diferentes questões que levem o estudante a praticar uma ação na direção do conhecimento a ser aprendido. Esse processo é o que leva o estudante a ter contato com o objeto de estudo que neste caso são os temas da geometria plana e espacial da Educação Básica (Miguel \& Mendes, 2010).

A prática sociocultural em estudo aqui é a atividade artística de um dos mais respeitados pintores de todos os tempos, Leonardo da Vinci, cuja atividade não se resumia a elaboração de pinturas, mas na busca por analogias que fundamentassem sua arte. Tais analogias eram buscadas nas ciências, principalmente na matemática.

Em suma uma UBP é materializada por um texto sucinto e claro que descreve uma prática sociocultural, preservando seus aspectos históricos e técnicos, bem como a autoria de tais técnicas. Essa prática histórica é recriada por esse relato e conectada, por meio de uma série de questionamentos propostos pelo professor, a práticas da atualidade presentes no contexto escolar. Esses questionamentos são postos pelo professor aos seus alunos, de forma a instigá-los na busca por soluções criativas.

Essas atividades poderão ser trabalhadas em grupos de 3 ou 4 alunos. Elas irão levar os alunos a investigar, pesquisar sobre os temas em estudo e os resultados de cada grupo podem 
ser partilhados com os demais em momento no qual eles poderão discutir sobre os resultados obtidos. Cabe ao professor conduzir a discussão com foco no objetivo a ser atingido.

Vejamos as atividades no formato de UBP sobre os desenhos de Leonardo da Vinci.

\section{Problematização 1: Leonardo da Vinci, seu tempo, sua obra e a matemática por ele estudada.}

Objetivos: Conhecer Leonardo e sua obra. Relacionar a geometria "de Leonardo" aquela da Escola Básica.

Leonardo da Vinci, famoso pintor renascentista, nasceu em 15 de abril de 1452 na cidade de Vinci na região da toscana na Itália. Filho ilegítimo de Ser Piero da Vinci (tabelião em Florença) com uma camponesa chamada Caterina, foi criado pelos avós no lugar onde nasceu. Após sua morte em 23 de abril de 1519 em Amboise na França, seus estudos e anotações foram herdados por seu amigo Francesco Melzi. Tais anotações constituíam uma coleção com cerca de 13.000 páginas das quais, atualmente, conhece-se o paradeiro de mais ou menos 7000, boa parte delas reunidas em Códices em bibliotecas da Itália e de outros Países (Isaacson, 2017; White, 2002).

Dentre essas coleções, está o Códice Atlântico ${ }^{7}$ que reúne estudos e desenhos de diferentes áreas de conhecimento pelas quais Leonardo transitava com excelência. $\mathrm{O}$ referido Códice é formado por 1119 folhas com anotações de Leonardo reunidas em um único volume por Pompeo Leoni no final do século XVI em Milão e reúne uma coleção de documentos que abarcam praticamente toda a vida artística e científica de Leonardo, produzidos por ele no período de 1478 a 1519 (41 anos, aproximadamente). Contém estudos e apontamentos práticos e teóricos sobre temas como: arquitetura, arte da guerra, mecânica, astronomia, hidráulica, óptica, anatomia, botânica, zoologia, estudos sobre o voo, estudos sobre a água, textos literários, anotações autobiográfica, perspectiva, aritmética e geometria (Isaacson, 2017; Bagni \& D'amore, 2012).

a) $\mathrm{O}$ que você sabe sobre o período do renascimento? Porque esse período tem esse nome? Pesquise e cite algumas características desse período histórico!

b) Você já havia escutado falar em Leonardo da Vinci? O que você sabe sobre ele?

\footnotetext{
${ }^{7}$ O Códice Atlântico é a maior coleção de desenhos e estudos de Leonardo da Vinci.
} 
c) Na sua opinião Leonardo da Vinci é considerado um dos maiores pintores de do renascimento e de todos os tempos? Por quê?

d) Você conhece alguma pintura famosa de Leonardo da Vinci? Quais?

e) Você sabia que Leonardo, havia feito estudos sobre alguns temas científicos além de ter sido pintor? Qual dentre os temas que ele estudou lhe chama mais a atenção? Escolha um deles e pesquise sobre ele!

f) Você sabe algo sobre o Códice Atlântico? Já havia ouvido falar nesse manuscrito? Vamos conhece-lo um pouco?

g) Faça uma busca na internet com o tema "Códice Atlântico" e selecione "imagens". Você deverá encontrar imagens das folhas do Códice. Que folhas você encontrou? Quais lhe chamam mais atenção e por quê?

h) Há dentre essas folha alguma que lhe lembra algo que você estudou nas aulas de matemática? Mostre essas folhas e diga, o que elas têm a ver com a matemática que você estudou?

i) Agora me fale uma coisa, quais dessas folhas selecionadas por você tem relação com a geometria que você conhece? Que elementos ou assuntos de geometria você consegue identificar nas imagens?

j) o livro didático que você está usando atualmente tem os conteúdos de geometria que você encontrou nas folhas do Códice Atlântico? Quais?

k) O que você achou desta atividade? Que aprendizados você obteve com ela?

\section{Problematização 2: a geometria da folha 100r do Códice Atlântico de Leonardo da Vinci}

Objetivos: Investigar que geometria está refletida na folha 100r do Códice Atlântico. Estabelecer relações entre essa geometria e aquela estudada na Educação Básica.

Como já foi dito anteriormente Leonardo fez estudos em algumas áreas como óptica, arquitetura, hidráulica e geometria. Esses estudos foram registrados por ele em milhares de folhas que contém anotações e desenhos e que hoje se encontrem em coleções pelo mundo todo em Bibliotecas, Museus e em propriedades particulares. Uma dessas coleções é o Códice Atlântico que reúne mais de mil dessas folhas com temas variados. 
A folha 100r é uma dentre as folhas do referido Códice que trata principalmente de dois temas: a construção de uma espécie de lâmina, como um formão, para corte ou entalhe de madeira, mármore e outros materiais, possivelmente foi pensada por Leonardo para a utilização em atividades como a escultura por exemplo. Além desse tema, há desenhos na folha que tratam da geometria e algumas anotações feitas por Leonardo nas quais ele fala sobre os desenhos e sobre outras coisas que não têm relação direta com os desenhos. Veja a folha!

Dentre as anotações de Leonardo há algumas que se referem a diagonal do quadrado e ao volume de sólidos geométricos. Sabemos que é difícil ler o que está escrito na folha, por isso, essa leitura já foi feita por um pesquisador Italiano chamado Algusto Marinoni que transcreveu as anotações de Leonardo. A partir dessa transcrição, fizemos uma tradução para que você tivesse acesso ao conteúdo da folha. Em uma dessa anotações Leonardo se refere a uma relação entre quadrados e nas outras ele fala sobre pirâmides, cones, cilindros e prismas para propor uma relação entre esses sólidos geométricos. Os trechos estão traduzidos a seguir e estão escritos ao lado do primeiro desenho geométrico da folha que é o aquele que tem um triangulo inscrito em um retângulo dividido em linhas horizontais e verticais.

\section{Bloco 1 de questões: Aspectos gerais e geométricos}

a) Observe a folha 100r! O que ela lhe provoca? Quando você olha para ela que lembranças ou sentimentos você tem?

b) O fácil entender o que Leonardo fez na folha? Os desenhos são compreensíveis?

c) destaque um desenho que lhe chamou mais atenção! O que é interessante nesse desenho e por que? 
d) Quais dos desenhos da folha lhe lembram aqueles das aulas de geometria? Que geometria você reconhece nesses desenhos?

e) Considere os seguinte elementos de geometria: ponto, reta, ângulo, seguimento de reta, horizontal, vertical, diagonal, triângulo, triângulo retângulo, triângulo equilátero, triangulo isósceles, retângulo, quadrado, circulo, circunferência, esfera, cilindro, cone, prisma e pirâmide. Agora observe a folha! Faça marcações e anotações na folha e em outro papel e diga: quais desses elementos de geometria você identifica na folha 100r?

\section{Bloco 2 de questões: Geometria Plana}

f) Há algum desenho na folha que lhe remete a medição de área de figuras geométricas planas? Que desenho é esse? Como a medição da área dessa figura pode ser feita, considerando o desenho de Leonardo? E considerando a fórmula para medição de área? Os resultados encontrados são os mesmos?

g) Você sabe o que é um quadrado? E um retângulo? Qual a diferença entre eles? Como é possível calcular a diagonal de um quadrado ou de um retângulo?

h) Dentre os desenhos de Leonardo há um que lembra mais um quadrado, qual é? Olhe para ele e o desenhe em seu caderno. Considerando o que Leonardo, qual a área e a diagonal desse quadrado?

i) Em uma de suas anotações, Leonardo escreve que "o lado de um quadrado é a diagonal de um quadrado subduplo e a metade da diagonal do quadrado é o lado do quadrado a esse primeiro também subduplo". Perceba que foram destacadas algumas palavras na frase de Leonardo. Dentre elas há alguma que você não conhece? Qual seria o significado dessas palavras que você não conhece?

j) A anotação de Leonardo acima trata de uma relação entre quadrados. Como você descreveria essa relação?

k) O que seria um quadrado subduplo? E um quadrado duplo?

1) Essa anotação de Leonardo se refere a área ou ao perímetro do quadrado? Ou a ambos?

m) desenhe dois quadrados em seu caderno e diga: o que significa, afinal, essa relação entre quadrados a qual Leonardo se refere?

\section{Bloco 3 de questões: Geometria espacial}

i) Você já estudou geometria espacial? Do que ela trata? 
k) Pirâmide, prisma, cilindro e cone são sólidos geométricos! Você conhece esses sólidos? Faça desenhos ou anotações e diga, o que é cada um deles para você?

1) Os sólidos geométricos têm características que os difere das figuras geométrica planas, que características são essas?

m) Como é calculado o volumes dos sólidos geométricos mencionados no item $\mathrm{k}$ ?

n) Dentre as anotações na folha 100r, Leonardo faz três que se referem aos sólidos geométricos a primeira é "o maior cone que pode ser feito no cilindro será igual a um terço da quantidade do cilindro”. Analise essa afirmação! Ela pode ser comprovada geometricamente? Estude a geometria do cilindro e do cone e diga: como essa relação pode ser feita?

o) A figura $(7)^{8}$ retrata um recipiente de forma cilíndrica que possui três marcações que o dividem em três partes de mesmo volume, cada uma com um terço do volume do cilindro inicial. Essas partes são cilindros que têm altura igual a um terço da altura do cilindro inicial. Esse recipiente recebe um volume de líquido até atingir a altura da primeira faixa, ou seja, até encher o cilindro B. Observe a figura e diga: qual a relação entre ela e as anotações de Leonardo dos itens $n$ e $p$ ?

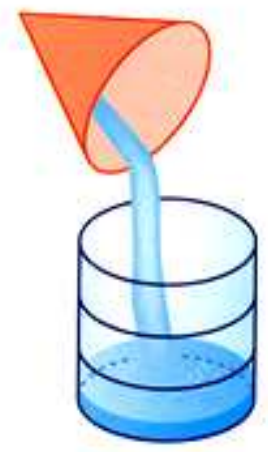

Figura 7: cone e cilindro

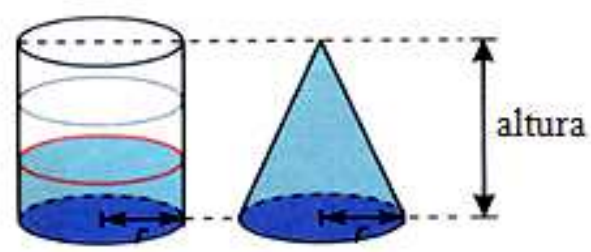

p) A segunda afirmação de Leonardo é "E a terça parte da altura do cilindro será, portanto, igual a seu maior cone”. Essa afirmação tem relação com a primeira? Que relação é essa? Explique, como essa relação pode ser feita?

q) $\mathrm{Na}$ terceira anotação Leonardo escreve: A pirâmide maior, sobre a base do cubo ou de outro corpo retangular, tem volume igual a terça parte desse corpo". Quando Leonardo fala “corpo retangular" ele se refere aos prismas. Analise essa afirmação de acordo com a geometria da pirâmide e do prisma e diga: como ela pode ser demostrada?

${ }^{8}$ Fonte das figuras 7 e 8: https://escolaeducacao.com.br/geometria-espacial. Acesso em 25/03/2020. 
r) Considere a figura 8. Ela apresenta dois prismas retangulares e uma pirâmide de base retangular. Ao que essa figura lhe remete? Faça uma descrição da figura! Por que os prismas têm faixas horizontais? Essa faixar são para ornamentar o prisma? Essa figura tem alguma relação com a anotação de Leonardo do item $q$ ? Que relações podem ser estabelecidas?

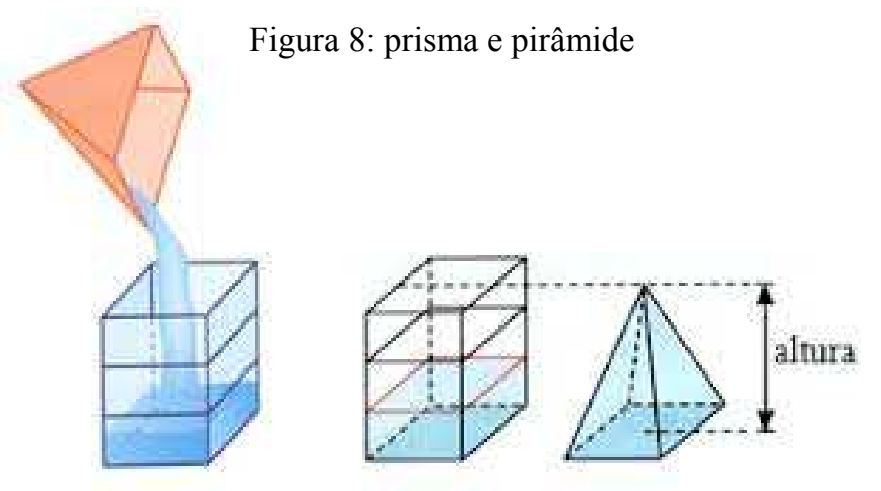

s) As anotações destacadas anteriormente foram feitas por Leonardo da Vinci a partir de estudos feitos por eles em obras de matemática como Os elementos de Euclides. Você conhece essa obra? Do que ela trata? Tente verificar em Os elementos se as anotações de Leonardo têm relação com o seu conteúdo.

t) O que você achou desta atividade? Que aprendizados você obteve com ela?

\section{Reflexões}

Para iniciar o final, destaco as contribuições que este trabalho teve para a minha formação, pois entendo que ao terminar um trabalho somos outro e melhor do ponto de vista do ato de aprender. Parece estranho porque quando se faz um texto acadêmico para comunicar o resultado de uma investigação, se faz para o outro, para o leitor que é quem você quer atingir, mas não só para ele, pois a trabalho de feitura do texto atinge que o faz, o modifica e o terna melhor do ponto de vista do aprendizado. Escrever um texto não é tarefa simples, exige concentração, dedicação e muito energia para conseguir comunicar o que se pretende, no meu entender relatar os resultados é mais complexo do que a própria investigação. Por isso, a escrita deste texto exigiu bastante de minha cognição, me fez pensar, refletir, avançar e recuar, duvidar, mas também afirmar e isso é o aprender e por isso eu aprendi com o trabalho que fiz.

Destaco, ainda a importância deste trabalho para o campo de estudos e pesquisas em Educação Matemática, pois julgo ser uma é uma contribuição importante e inovadora, pois em um recente levantamento que fiz (que será publicado oportunamente) não encontrei no Brasil, 
trabalhos que tomem o Códice Atlântico de Leonardo da Vinci com foco no ensino de geometria. Além desse aspecto a relevância do trabalho para o campo encontra-se em ser um trabalho que se preocupa com o ensino de matemática, que é um dos pilares de fundação desse campo.

As contribuições para a formação de professores de matemática, também se destacam, pois neste trabalho, nos preocupamos em apresentar uma interpretação dos desenhos de Leonardo, mas também em dizer ao professor da Educação Básica como ele poderá utilizar essa interpretação para ensinar geometria para seus alunos. As atividades que elaboramos são sugestões que poderão ser adaptadas pelo professor ao seu contexto de forma a otimizar sua eficácia. A partir delas, o professor poderá elaborar a sua atividade da forma que julgar mais conveniente, pois nosso proposito com as atividades e fornecer uma proposta uma possibilidade e não um modelo a ser seguido à risca.

As relações que estabelecemos com a geometria escolar quando mencionamos os documentos curriculares oficias e o livro didático de matemática, poderão contribuir com o ensino, na perspectiva de complementação e não de substituição do documento e livros. Nossa proposta é que a interpretação dos desenhos e anotações de Leonardo bem como as atividades a serem elaboradas a partir dessa interpretação, poderão complementar o modo como os documentos oficiais e livros didáticos apresentam e orientam o ensino de geometria na Educação Básica.

Esperamos contribuir com a formação de todos aqueles que lerem este texto, se não pela utilização imediata da proposta e de seus resultados, mas pelo fato de, a partir dessa leitura, pensarem e repensarem sua prática docente objetivando sua inovação, complementação e/ou ressignificação. De forma especial, esperamos atender as expectativas dos professores de matemática da Educação Básica, por uma metodologia que promova o aprendizado que desejam para seus alunos com nossa proposta metodológica para o ensino de geometria. Contando com adequação das atividades propostas para outros conteúdos matemáticos, outros níveis de ensino e, porque não, para outras disciplinas do currículo escolar.

Como já foi mencionado, este trabalho faz parte de uma investigação mais ampla e apresenta resultados parciais que serão complementados com outras publicações que aprofundarão o tema devido sua amplitude e relevância para o campo de pesquisa. 


\section{Referências}

Bagni, G. T.; D’amore, B (2012). Leonardo e a matemática - São Paulo, SP. Editora Livraria da Física.

Barros, J. A. (2004). O campo da história: especialidades e abordagens. Petrópolis, RJ: Vozes.

Brasil (2018). Ministério da Educação. Base Nacional Comum Curricular (BNCC).

Brasil (2007) Ministério da Educação. Parâmetros Curriculares Nacionais para o Ensino Médio $(\mathrm{PCN}+)$ : Ciências da natureza, Matemática e suas tecnologias.

Euclides (2009). Os elementos. Tradução e introdução de Irineu Bicudo, São Paulo, Editora da UNESP.

Euclides (1944). Os elementos. Tradução Frederico Commandino, São Paulo: Edições Cultura.

Isaacson, W. (2017). Leonardo da Vinci. Tradução de André Czarnobai. 1. Ed. - Rio de Janeiro: Intrínseca.

Mendes, I. A. (2012b). Pesquisas em história da Educação Matemática no Brasil em três dimensões. Quipu, vol. 14, núm. 1. pp. 69-92. janeiro-abril de 2012.

Mendes, I. A. (2010) Cartografias da produção em História da Matemática no Brasil: um estudo centrado nas dissertações e teses defendidas entre 1990-2010. Projeto de pesquisa (Bolsa produtividade CNPq). Natal: Universidade Federal do Rio Grande do Norte. Impresso.

Mendes, I. A. (2015). História da matemática no ensino: entre trajetórias profissionais epistemologias e pesquisas. São Paulo: Editora Livraria da Física.

Miguel, A.; Mendes, I. A. (2010) Mobilizing histories in mathematics teacher education: memories, social practices, and discursive games. In: ZDM Mathematics Education. v. 42. p. $381-392$.

Paiva, M. (2015). Matemática. 3 ed. - São Paulo: Moderna.

Sánchez, J. L. Almarza, M. B. (2008). O Códice Atlântico de Leonardo da Vinci (vol. 2) (Coleção O códice Atlântico de Leonardo da Vinci). Barcelona: Fólio.

Santaella, L. (2012). Leitura de Imagens. São Paulo: Editora Melhoramentos.

Santaella, L. (1995). O que é semiótica? 14 ed. São Paulo: Brasiliense. 
White, M. (2002). Leonardo o primeiro cientista. 4 ed. - Rio de Janeiro, RJ. Record.

Autor:

Jeová Pereira Martins

Mestrado em Educação em Ciências e Matemáticas pela Universidade Federal do Pará (2017). Doutorando em Educação em Ciências e Matemáticas pela Universidade Federal do Pará UFPA (2018-2021). Graduação em Licenciatura Plena em Matemática pela Universidade Federal do Pará (2004). Especialização em Matemática no Ensino Básico, pela Faculdade Integrada Brasil Amazônia (FIBRA/PA, 2016). Integrante do Grupo de Práticas Socioculturais e Educação Matemática (GPSEM/UFPA). Professor de Matemática da Educação Básica a partir de 2004, atuando desde 2008 em Escolas Públicas do Estado do Pará (Pará/Brasil). Mais informações no Currículo Lattes: http://lattes.cnpq.br/3909598558519646. ORCID: https://orcid.org/0000-0002-7151-8136. E-mail: Jeovapereira80@outlook.com 